\title{
Influência da vegetação no conforto térmico urbano em município do Sul do Tocantins
}

\author{
Influence of vegetation on thermal and urban comfort in a municipality in the south of Tocantins \\ Influencia de la vegetación en el confort térmico urbano en un municipio del sur de Tocantins
}

Recebido: 11/05/2021 | Revisado: 17/05/2021 | Aceito: 20/05/2021 | Publicado: 24/05/2021

\author{
Danillo Lopes Neres \\ ORCID: https://orcid.org/0000-0003-0866-0639 \\ Universidade de Gurupi, Brasil \\ E-mail: danillo-gpi@hotmail.com \\ Luma Rafaela Carvalho da Silva \\ ORCID: https://orcid.org/0000-0002-5440-6458 \\ Universidade de Gurupi, Brasi \\ E-mail: Luma.silvagpi@gmail.com \\ Miréia Aparecida Bezerra Pereira \\ ORCID: https://orcid.org/0000-0002-3035-6249 \\ Universidade de Gurupi, Brasil \\ E-mail: mireia@unirg.edu.br
}

\begin{abstract}
Resumo
O ambiente urbano deve ser um local onde o conforto do usuário seja alcançado. Em muitos casos, porém, os ambientes urbanos não oferecem condições adequadas de conforto, seja ele térmico, acústico, luminoso ou visual. A cidade em si é uma grande mudança climática, devido às grandes áreas pavimentadas e à diminuição dos espaços verdes, a camada de ar nas áreas urbanas tende a ser mais quente do que nas áreas rurais. Além disso, a atividade humana desenvolvida nas cidades gera profundas mudanças no clima local, que também podem alterar a temperatura e o regime de chuvas na região dessa forma, o objetivo desta pesquisa foi avaliar a influência da vegetação urbana na temperatura e umidade relativa do ar no município de Gurupi a fim de despertar a possibilidade de propor projetos urbanos e construções com uso de áreas arborizadas. Para análise e comparação da influência da vegetação nos aspectos de conforto térmico/temperatura e umidade do ar, as medições serão realizadas em cinco áreas na região central do município de Gurupi-TO, para o levantamento de dados, foi utilizado um Termômetro digital com a coleta dos parâmetros ambientais de temperatura e umidade relativa do ar. Quanto aos valores referentes à umidade relativa do ar, a área 01, apresentou média de $36 \%$, área 2, média de umidade em $34 \%$, na área 3, a média ficou em $34 \%$, na área 4 médias $38 \%$ e na área 5 médias de $40 \%$. Os resultados permitem auxiliar o planejamento da cidade de Gurupi, podendo ser adotada para proposição de espaços urbanos com maior qualidade de vida para a população.
\end{abstract}

Palavras-chave: Área verde; Arborização urbana; Conforto térmico.

\begin{abstract}
The urban environment must be a place where user comfort is achieved. In many cases, however, urban environments do not offer adequate conditions of comfort, be it thermal, acoustic, luminous or visual. The city itself is a major climate change, due to the large paved areas and the decrease in green spaces, the air layer in urban areas tends to be warmer than in rural areas. In addition, the human activity developed in cities generates profound changes in the local climate, which can also alter the temperature and rainfall in the region in this way. The objective of this research was to evaluate the influence of urban vegetation on the temperature and relative humidity of the air. in the municipality of Gurupi in order to awaken the possibility of proposing urban projects and constructions using wooded areas. For analysis and comparison of the influence of vegetation on the aspects of thermal comfort / temperature and air humidity, the measurements will be carried out in five areas in the central region of the municipality of Gurupi-TO, for data collection, a digital thermometer will be used. collection of environmental parameters of temperature and relative humidity of the air. As for the relative humidity values, area 01 showed an average of $36 \%$, area 2 , average humidity in $34 \%$, in area 3 , the average was $34 \%$, in area 4 averages $38 \%$ and in area 5 averages of $40 \%$. The results allow to assist the planning of the city of Gurupi, which can be adopted for proposing urban spaces with a higher quality of life for the population.
\end{abstract}

Keywords: Green area; Urban afforestation; Thermal comfort.

\section{Resumen}

El entorno urbano debe ser un lugar donde se logre la comodidad del usuario. En muchos casos, sin embargo, los entornos urbanos no ofrecen las condiciones adecuadas de confort, ya sea térmico, acústico, luminoso o visual. La ciudad en sí es un gran cambio climático, debido a las grandes áreas pavimentadas y la disminución de espacios verdes, la capa de aire en las áreas urbanas tiende a ser más cálida que en las áreas rurales. Además, la actividad humana desarrollada en las ciudades genera cambios profundos en el clima local, que también pueden alterar la temperatura y las precipitaciones en la región de esta manera. El objetivo de esta investigación fue evaluar la influencia de la vegetación urbana en la 
temperatura y la temperatura relativa. humedad del aire en el municipio de Gurupi con el fin de despertar la posibilidad de proponer proyectos y construcciones urbanas utilizando áreas boscosas. Para el análisis y comparación de la influencia de la vegetación en los aspectos de confort térmico / temperatura y humedad del aire, las mediciones se realizarán en cinco áreas de la región central del municipio de Gurupi-TO, para la recolección de datos se utilizará un termómetro digital. Ser utilizado Recolección de parámetros ambientales de temperatura y humedad relativa del aire. En cuanto a los valores de humedad relativa, el área 01 presentó un promedio de 36\%, el área 2, humedad promedio en $34 \%$, en el área 3 el promedio fue de $34 \%$, en el área 4 promedios de $38 \%$ y en el área 5 promedios de $40 \%$. Los resultados permiten ayudar a la planificación de la ciudad de Gurupi, pudiendo ser adoptada para propuesta de espacios urbanos con mayor calidad de vida para la población.

Palabras clave: Area verde; Forestación urbana; Comodidad térmica.

\section{Introdução}

O bem-estar nas áreas urbanas está amplamente relacionada ao conforto térmico, que representa o estado mental de um indivíduo no ambiente circundante (Ashrae, 2004). No entanto, devido à falta de planejamento espacial adequado, má implantação da morfologia urbana e a falta de cobertura vegetal muitas cidades estão se tornando vulneráveis à formação de fontes de calor. Este fenômeno causa desconforto térmico e consequências negativas para a população: na saúde humana, e na natureza social em geral, afetando o desempenho no trabalho até o uso dos espaços públicos (Souza e Nery, 2010).

Os parâmetros que influenciam um bom conforto térmico podem ser divididos em fatores pessoais e fatores ambientais (Romero, 2006). O homem, assim como ser homeotérmico, tem a obrigação de manter constante a temperatura interna durante a perda de calor que é produzido pelo metabolismo para o ambiente, sem recurso a mecanismos termorreguladores (Barbosa, 2018).

As atividades humanas são um dos principais fatores que impulsionam as mudanças climáticas cada vez mais rapidamente (Silva, 2015). O espaço construído, ao contrário do espaço natural, impacta o meio ambiente de várias maneiras, tais como: através do uso de revestimentos impermeáveis, supressão vegetativa, alteração de albedo e rugosidade, troca de corpos d'água, além do acumulo de poluentes, contribui para um maior desconforto térmico (Chu et al., 2017 apud Alves et. al., 2019).

As áreas urbanas devem ser geradoras de frescor e tranquilidade para os seus usuários para que o equilíbrio seja alcançado. Em certos casos, porém, os ambientes urbanos não oferecem condições adequadas de conforto, seja ele térmico, acústico, luminoso ou visual. A cidade em si é uma grande mudança climática, devido às grandes áreas pavimentadas e à diminuição dos espaços verdes, a camada de ar nas áreas urbanas tende a ser mais quente do que nas áreas rurais. Além disso, a atividade humana desenvolvida nas cidades gera profundas mudanças no clima local, que também podem alterar a temperatura e o regime de chuvas na região (Silva; Xavier; de Alvarez, 2015).

Vários autores mostram a importância das áreas verdes urbanas para atenuação do ar e melhoria do conforto térmico e consequentemente uma melhoria na qualidade de vida do ser humano (Ochoa de La Torre, 1999; Labaki, 1999; Labaki, 2011; Romero, 2000; Shams, 2009; Minella, 2014; Minas, 2017). Segundo Lamberts et al (1998 apud Silva; Adário; Marques, 2019), a compreensão dos dois extremos calor e frio são essenciais para a elaboração de projetos que proporcionem melhores condições de conforto térmico aos indivíduos.

A arborização urbana é uma alternativa que pode contribuir para a paisagem urbana de várias maneiras, interagindo com os indivíduos por razões físicas e climáticas. As características da vegetação diminuem o impacto da radiação solar na superfície, amortecem o ruído, diminuem a poluição do ar e diminuem o consumo de energia em regiões quentes. Se bem planejada, a arborização também pode agregar valor às áreas urbanas e construir edifícios nas imediações (Cardoso; Jorge Filho, 2018).

Nesse sentido, a falta de vegetação, entre outros aspectos, é um dos fatores responsáveis pelas mudanças no clima urbano. A vegetação nas áreas urbanas é um importante componente do microclima, contribuindo para o aumento da umidade relativa do ar, a diminuição da temperatura e, consequentemente, para a melhoria do conforto térmico em ambientes tropicais. 
Dentre os benefícios da vegetação associada ao desenho urbano, nos estudos sobre o papel dos fragmentos florestais urbanos no conforto térmico na cidade de Campinas-SP, concluiu-se que a vegetação foi um fator relevante para o conforto térmico, sendo capaz de mitigar temperaturas elevadas do ar (Barbieri et al., 2018).

Vegetação em geral, devido à sua baixa capacidade calorífica e condutividade térmica bloqueia parcialmente a radiação solar, absorvendo parte dessa radiação pelas folhas e refletindo muito pouco do resto; a taxa de evaporação aumenta; e permitir a permeabilidade do vento, porém reduzindo sua velocidade, permite alterar as variáveis climáticas tornando o microclima ameno (Lima; Nunes; Soares, 2009).

Assim, a influência da vegetação não se limita ao ambiente urbano, uma vez que também se estende às edificações, o que pode melhorar o conforto térmico interno e, consequentemente, ainda permitir a redução dos gastos com energia com aparelhos de ar condicionado (Lima; Nunes; Soares, 2009).

O estado do Tocantins é conhecido pelas altas temperaturas registradas o ano inteiro, onde se destaca o município de Gurupi que apresenta clima quente com grandes períodos de estiagem. Diante disso, o objetivo desta pesquisa foi avaliar a influência da vegetação urbana na temperatura e umidade relativa do ar no município de Gurupi a fim de despertar a possibilidade de propor projetos urbanos e construções com uso de áreas arborizadas.

\section{Metodologia}

\subsection{Caracterização do município}

A área de estudo abordada foi realizada na na cidade de Gurupi (Figura 1), localizada no sul do Estado do Tocantins com distancia aproximada de 200 Quilômetros da capital, Palmas. O município fica no limite divisório de águas entre o Rio Araguaia e o Rio Tocantins, às margens da BR - 153 (Rodovia Belém - Brasília). Gurupi é a terceira maior cidade do Tocantins, sendo o polo regional de toda a região sul do Estado. Segundo o último censo do Instituo Brasileiro de Geografia e Estatística (IBGE), em 2010, a cidade possuía uma população estimada em 76755 habitantes e conta com uma área de 1.836 km².

O clima segundo a classificação de Koppen é tipicamente tropical megatérmico, quente e úmido durante todo o ano com período chuvoso entre os meses de outubro e abril e estiagem entre os meses de maio a setembro com pluviosidade média anual de $1483 \mathrm{~mm}$, em média. A temperatura média anual que varia entre a mínima de $12^{\circ}$ e a máxima de $30^{\circ} \mathrm{C}$, mas nos meses mais quentes do ano chega a $42^{\circ} \mathrm{C}$ à luz do dia, dependendo da época do ano.

\section{2 Área de estudo}

Para análise e comparação da influência da vegetação nos aspectos de conforto térmico/temperatura e umidade do ar, as medições foram realizadas em cinco áreas na região central do município de Gurupi-TO. Estas áreas possuem características diversas em relação à densidade da vegetação, tipos de pavimentação, presença de residências e estabelecimentos comerciais e circulação de pessoas e no total estão a uma distância da outra em aproximadamente 1,5 km. Devido à proximidade, pode-se considerar que as áreas de estudo, em geral, estão sujeitas as influências climáticas similares.

Essas áreas são:

Área 1: Praça do Centro Cultural Mauro Cunha, localizada na região central, em um local de intenso comércio e fluxo de pessoas, com unidades arbóreas isoladas e cuidados pela Prefeitura Municipal, (1)

Área 2: Centro comercial, localizado na região central, em um local de comércio e fluxo de pessoas, sem unidades arbóreas (2)

Área 3: Centro comercial, localizado na região central, em um local de intenso comércio e fluxo de pessoas, com unidades arbóreas no centro da avenida (3)

Área 4: Região central desprovida de arborização urbana e estritamente residencial e comercial (4) 
Área 5: Parque Mutuca, local bem arborizado, apresenta espécies de médio e grande porte, arbustos e canteiros gramados na base do caule (5)

Figura 1: Áreas urbanas analisadas. 1 - Praça do Centro Cultural Mauro Cunha; 2 - Centro comercial sem unidades arbóreas; 3 - Centro comercial com unidades arbóreas; 4 - Região central residencial; 5 - Parque Mutuca.
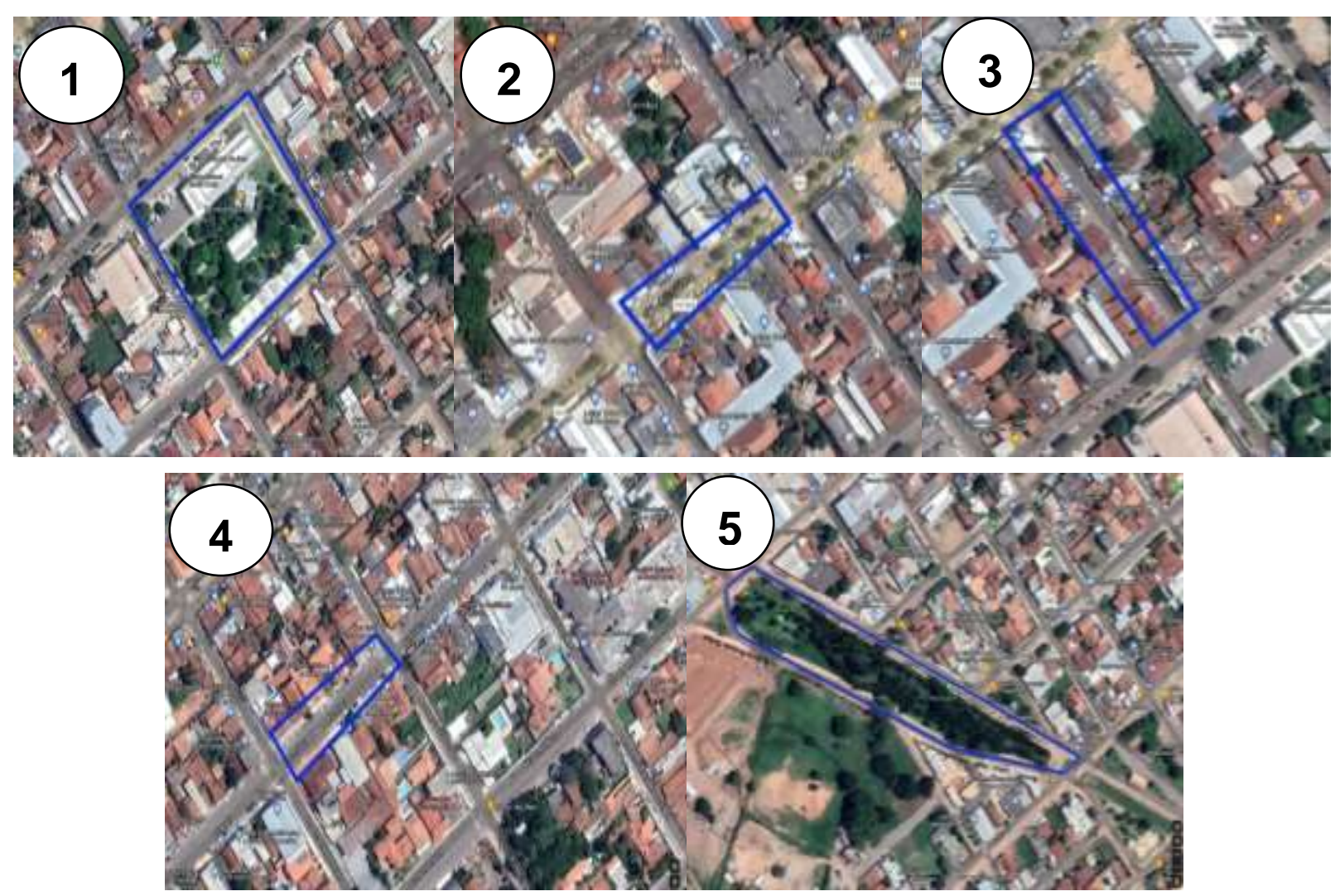

Fonte: Google Maps.

Para o levantamento de dados, foram utilizados um Termômetro digital com a coleta dos parâmetros ambientais de temperatura e umidade relativa do ar. O período representativo para esta pesquisa foi o da estiagem. A coleta de dados ocorreu nos meses de setembro e outubro, nos cinco locais e em três horários distintos ( 9 às $10 \mathrm{hs}, 12$ às $13 \mathrm{hs}$ e 17 às $18 \mathrm{hs}$ ). O termômetro foi posicionado a uma altura de 1,50 metros do solo para captura das variáveis.

Seguindo a metodologia de Gonçalves et al. (2012) modificada, os dados - temperatura e umidade relativa do ar foram registrados a cada 30 segundos durante 2 minutos na parte central de cada área com um tempo de deslocamento entre uma área e outra de aproximadamente 3 minutos, iniciando as medições conforme horários descritos acima.

Os resultados foram analisados no programa SigmaPlot para Windows versão 14.0

\section{Resultados e Discussão}

Para as áreas avaliadas por este estudo, temperatura e umidade relativa do ar, os resultados obtidos foram significativos e demonstraram que a vegetação arbórea influência de forma considerável os parâmetros analisados. A Figura 1 mostra os valores identificados para cada local analisado no meio urbano, no qual as variações foram consideradas estatisticamente significativas. quanto à temperatura medida em graus Celsius $\left({ }^{\circ} \mathrm{C}\right)$, na área 1 nos três horários analisados $(9-10 \mathrm{hs} / 12-13 \mathrm{hs} / 17-18 \mathrm{hs})$ a qual 
apresenta árvores próximas e canteiros gramados, a temperatura ficou no intervalo de 34 a $36{ }^{\circ} \mathrm{C}$ sendo que no horário mais fresco para esta área ocorreu ao final do dia com uma diferença de mais de $2{ }^{\circ} \mathrm{C}$ entre este e o horário mais quente (12-13hs).

Na área 2 nos três horários analisados (9-10hs/ 12-13hs/ 17-18hs) a qual apresenta comércios sem a presença de vegetação, a temperatura ficou no intervalo de 36 a $39^{\circ} \mathrm{C}$ e foi notado que a diferença de temperatura é mais de $3{ }^{\circ} \mathrm{C}$ entre este e o horário mais quente (12-13hs). Já na área 3 a qual apresenta grande parte de comércio e fluxo de veículos com pouca presença de vegetação, a temperatura ficou entre 36 e $39{ }^{\circ} \mathrm{C}$ com horário mais fresco no final do dia com diferença de mais de $3{ }^{\circ} \mathrm{C}$ comparado ao horário mais quente (12-13hs).

Quanto a área 4 a temperatura medida em graus Celsius $\left({ }^{\circ} \mathrm{C}\right)$ nos três horários a qual apresenta pontos residenciais e comerciais com pouca vegetação ocorreu que a temperatura ficou no intervalo de 34 a $36^{\circ} \mathrm{C}$ registrando a menor temperatura na parte da manhã (9 às 10hs) com diferença de mais de $2{ }^{\circ} \mathrm{C}$ em relação ao horário mais quente (12-13hr). E por fim na área 5 , local que apresenta bastante vegetação rasteira e arvores a temperatura ficou entre 33 a $35^{\circ} \mathrm{C}$ registrando menor temperatura pela parte da manhã (9 às 10hs) com diferença de mais de $2^{\circ} \mathrm{C}$ em comparação ao horário mais quente (12-13hs). Foi essa área 5 que registrou a menor temperatura em comparação aos demais locais.

Figura 2. Variações de temperaturas de acordo com a área e diferentes horários ao longo do dia. Área 1 - Praça do Centro Cultural Mauro Cunha, 2 - Centro comercial (Rua 3 entre Goiás e Maranhão), 3 - Centro comercial (Avenida Goiás entre ruas 03 e 04), 4 - Ponto residencial e comercial (Avenida Piauí entre ruas 5 e 7) e 5 - Parque Mutuca.

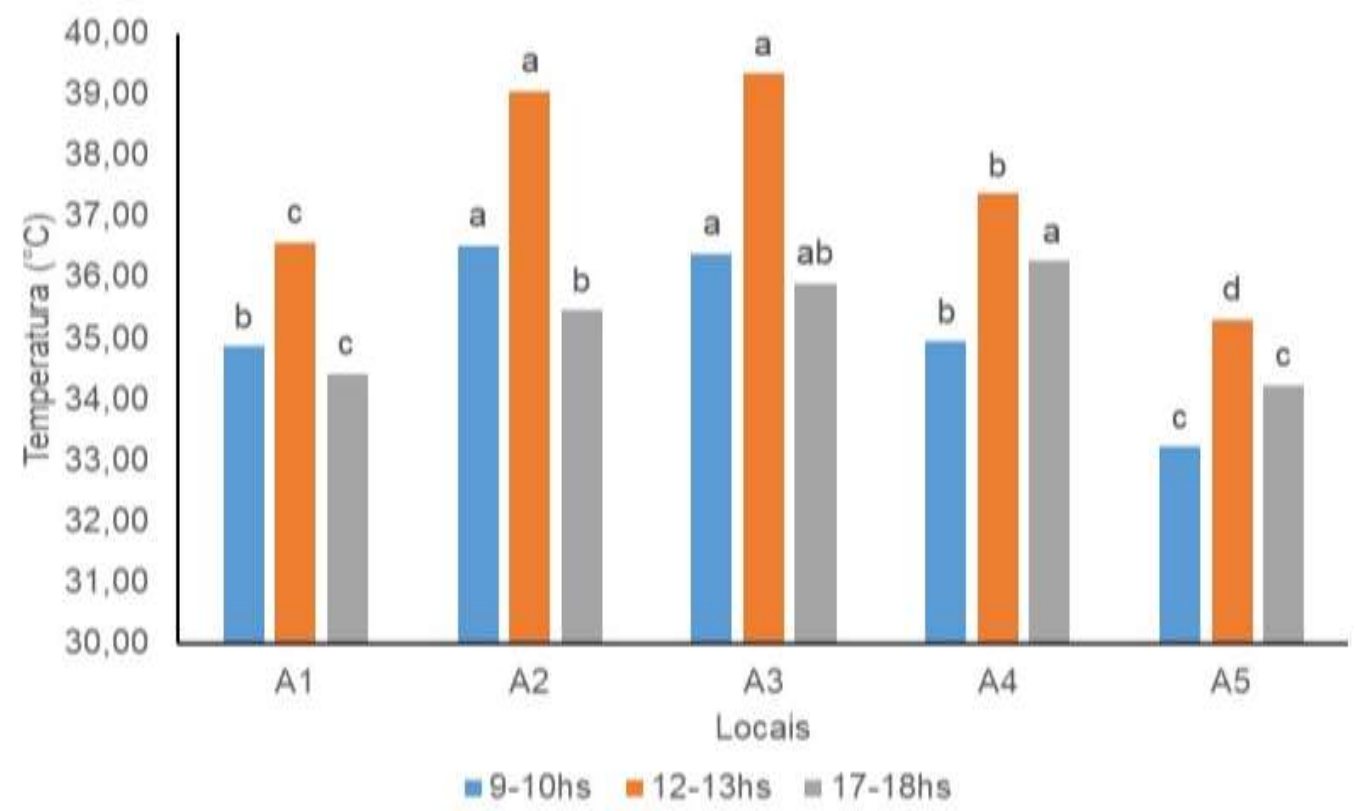

Fonte: Autores (2021).

Através da análise dos resultados, pode-se verificar que no sombreamento promovido pela arborização urbana, nestes locais, obteve resultado satisfatório na redução da temperatura do ar, pois o sombreamento é capaz de promover a diminuição das temperaturas de superfície dos locais sombreados conforme demostrado na Figura 1.

Martelli e Santos Jr (2015) estudaram as diferenças de temperatura e umidade relativa do ar em três locais da região central do município de Itapira-SP, destacando-se pela diferença da vegetação arbórea existente e concluíram que a arborização influencia os valores de temperatura e umidade relativa do ar, indicando uma necessidade de arborização na área urbana, como condicionante de conforto térmico. Os dados observados estão de acordo com o estudo de Bonametti et al. (2020), onde verificouse que as áreas arborizadas favoreceram uma temperatura inferior a locais sem arborização. 
Segundo Labaki et al. (2011), há impacto da vegetação no conforto térmico urbano devido as árvores, isoladas ou em grupos, atenuarem grande parte da radiação incidente, impedindo que sua totalidade atinja o solo ou as construções. Essa vegetação propicia resfriamento passivo em uma edificação por meio do sombreamento e da evapotranspiração. O sombreamento atenua a radiação solar incidente e, consequentemente, o aquecimento das superfícies, reduzindo a temperatura superficial destas, portanto, a emissão de radiação de onda longa para o meio. Através da evapotranspiração, ocorre o resfriamento das folhas e do ar adjacente, devido à retirada de calor latente.

Podemos concluir que no local 5 houve resultados significativos e foi a área que apresentava maior ocupação de vegetação e o clima apresentou temperaturas mais frescas em relação aos locais (2, 3 e 4) que não tinha vegetação nenhuma por perto.

Figura 3. Variações de umidade relativa do ar de acordo com a área e diferentes horários ao longo do dia. Área 1 - Praça do Centro Cultural Mauro Cunha, 2 - Centro comercial (Rua 3 entre Goiás e Maranhão), 3 - Centro comercial (Avenida Goiás entre ruas 03 e 04), 4 - Ponto residencial e comercial (Avenida Piauí entre ruas 5 e 7) e 5 - Parque Mutuca.

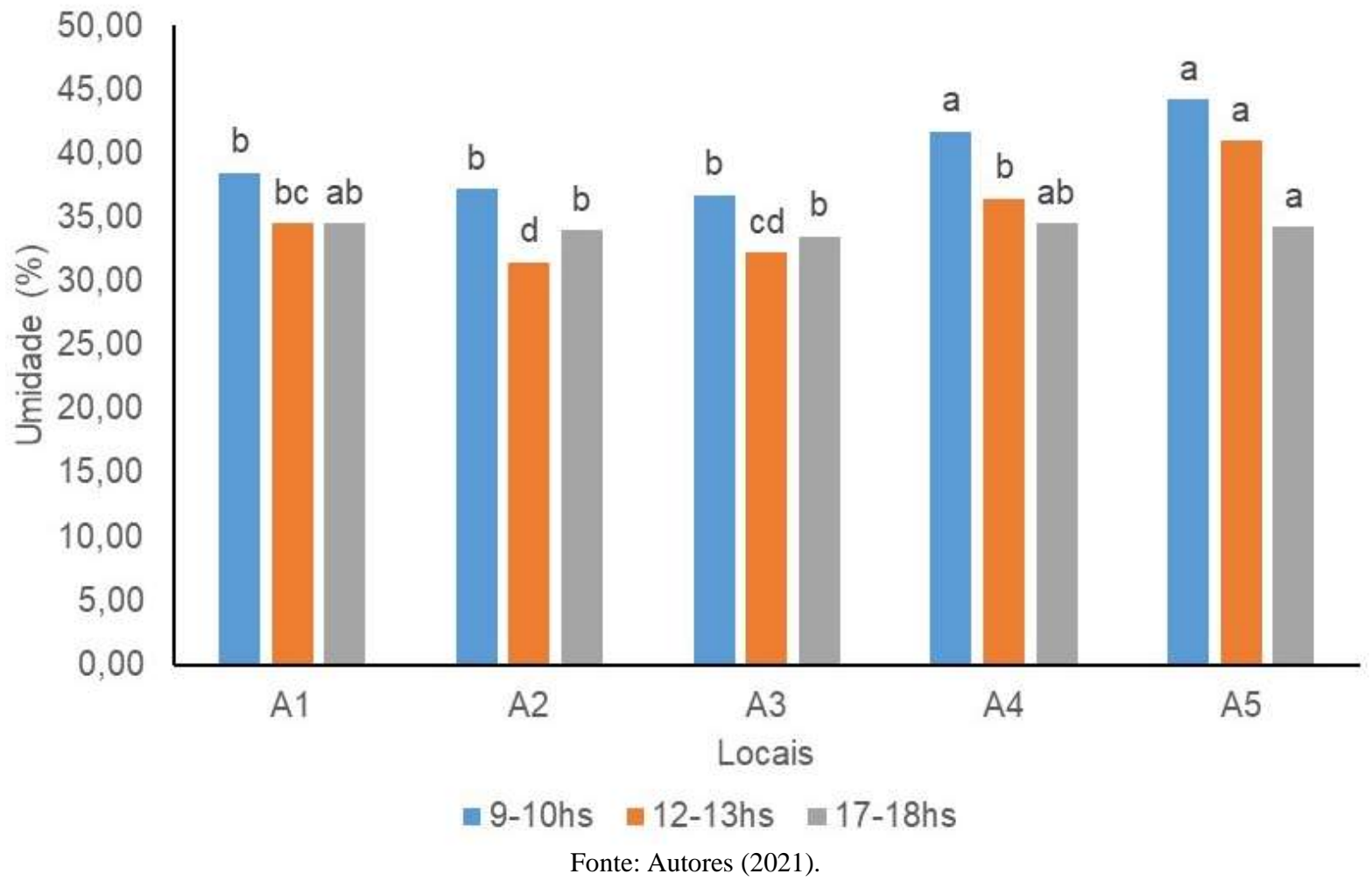

Quanto aos valores referentes à umidade relativa do ar, a área 01, apresentou média de 36\%, área 2, média de umidade em 34\%, na área 3, a média ficou em 34\%, na área 4 médias 38\% e na área 5 médias de 40\% (Figura 2). Para a análise da variável umidade relativa do ar coletado através de um termômetro digital, observa -se que locais que apresenta vegetação obteve êxito no aumento da umidade do ar. Quando a vegetação na cidade é distribuída na forma de reservas naturais, parques urbanos, jardins e outros, conforme área 3 deste estudo, o balanço de energia de toda a cidade pode ser modificado pela adição de mais superfícies evaporativas, mais radiação absorvida pode ser dissipada na forma de calor latente e a temperatura urbana reduzida (YU e HIEN, 2006).

Freitas et al. (2013), também observaram que os pontos que apresentaram as maiores médias de temperatura e as menores taxas médias de umidade relativa do ar estavam em locais com intensa área construída, sendo observado neste estudo, que a área onde a umidade relativa do ar estava com os menores índices mostra-se densamente construída e com poucas ou sem árvores. 
Isso mostra a importância da cobertura vegetal em áreas urbanas com intuito de aumentar o conforto térmico dos espaços urbanos e, consequentemente, da população, uma vez que influencia na redução de temperatura e na umidade do ar.

Conforme Masiero \& Souza (2018), do ponto de vista do desenho urbano, diversos fatores podem ser gerenciados, modificados e controlados pela ação humana a fim de se obter ganhos de qualidade de vida e bem-estar aos habitantes de determinado local. Assim, é importante que o planejamento urbano considere estratégias que busquem a criação de áreas verdes, com vegetação e arborização suficientes para favorecer melhores condições climáticas e de conforto térmico

\section{Conclusão}

Ficou confirmado que a área 5 registrou a menor temperatura nos três horários avaliados por possuírem um espaço com maior vegetação arbórea, diferente das áreas 2 e 3 onde foram verificadas as maiores temperaturas, devido nestes espaços possuírem alta densidade de edificações e pouca ou nenhuma espécie arbórea. A umidade relativa do ar apresentou um padrão inverso ao da temperatura onde os maiores valores foram registrados na área 5 com baixa densidade de edificações e grande presença de espécies arbóreas.

Tais resultados demostraram que a vegetação arbórea influencia os valores de temperatura e umidade relativa do ar na região central do município de Gurupi-TO no período em que foi realizado o estudo. Estes permitem auxiliar o planejamento da cidade, podendo ser adotada para proposição de espaços urbanos com maior qualidade de vida para a população.

\section{Referências}

Barbieri, L. R., Riboldi, L., Sekine, E. S., \& Bueno, P., (2018). Influência da vegetação no conforto térmico da UTFPR Campus-Campo Mourão-pr. Revista de Geografia, Meio Ambiente e Ensino, 8(3), 40-49.

Bonametti, J. H., (2020). Arborização urbana. Revista Terra \& Cultura: Cadernos de Ensino e Pesquisa, 19(36), 51-55.

Cardoso, N. S., \& Jorge Filho, H. O., (2017). A influência da vegetação no conforto térmico para a condição microclimática de cascavel/pr. Revista Thêma et Scientia, 7(1E), 90-104.

Freitas, A. F., Melo, B. C. B., Santos, J. S., \& Araújo L. E., (2013). Avaliação microclimática em dois fragmentos urbanos situados no Campus I e IV da Universidade Federal da Paraíba. Revista Brasileira de Geografia Física. 6(4), 777-92.

Labaki, L. C., Santos, R. F. D. S. \& Bueno-Bartholomei, C. L. (2011).

Lima, D. C. R., Nunes, L. A., \& Soares, P. F., (2009). Avaliação da influência da vegetação no conforto térmico em espaços livres. Simpósio de Pós-graduação em Engenharia Urbana, Maringá.

Martelli, A., \& Santos Júnior, A. R., (2015). Arborização Urbana do município de Itapira-SP: perspectivas para educação ambiental e sua influência no conforto térmico. REGET/UFSM, 19(2), 1018-31.

Masiero, E., \& Souza., L. C. L. (2018). Mapping humidity plume over local climate zones in a high-altitude tropical climate city, Brazil. Ambiente Construído, 18(4), 177-197. http://dx.doi.org/10.1590/s1678-86212018000400300.

Silva, B. A., Xavier, T. C., \& de Alvarez, C. E., (2015). A influência da vegetação no conforto térmico para a condição microclimática de Vitória (ES). Periódico Técnico e Científico Cidades Verdes, 3(8). 